\title{
Annual circulating testosterone levels in captive and free- ranging male armadillos (Dasypus novemcinctus)
}

\author{
N. M. Czekala, J. K. Hodges, G. E. Gause and B. L. Lasley \\ Research Department, San Diego Zoo, P.O. Box 551, San Diego, California 92112, U.S.A.
}

\begin{abstract}
Summary. Mean circulating concentrations and seasonal changes in plasma testosterone over 3 years were similar in free-ranging and captive male armadillos. The highest concentrations were seen in the summer months, i.e. at the time of maximum breeding, but the relatively high values at other times and the inability of ACTH to restore dexamethasone-suppressed testosterone concentrations confirms that testicular function continues throughout the year. There was a gradual rise in plasma testosterone to adult levels from the 5 th to the 9 th month of life in captiveborn males, indicating that sexual maturity is reached within the first year of life and that captivity is not deleterious to Leydig cell function.
\end{abstract}

\section{Introduction}

The annual reproductive cycle of the nine-banded armadillo (Dasypus novemcinctus) has been described as a concentrated breeding season in the summer months followed by a 3-4-month pre-implantation and an equal, if not longer, post-implantation period (Hamlett, 1932). More recent studies in the male show an increase in testis size during the breeding season (McCusker, 1976) although active spermatogenesis and little change in the morphology of the interstitial tissue are found throughout the year (Weaker, 1977). It would appear then that, compared to other male mammals with well-defined breeding seasons (see Schanbacher \& Ford, 1976; McMillan, Seal, Rogers \& Erickson, 1976; Bogart, Kumamoto \& Lasley, 1977; Neal, Murphy, Moger \& Oliphant, 1977), the male armadillo exhibits a less complete gonadal quiescence during the non-breeding season.

This study was conducted to measure the circulating testosterone levels in free-ranging male armadillos and to correlate these values with the stage of the breeding season and changes in testicular volume. In addition, longitudinal samples were evaluated in immature and mature males in captivity in an attempt to ascertain if testicular function is in any way impaired by the captive state in this species.

\section{Materials and Methods}

\section{Animals and sample collection}

Mature male and female armadillos were shipped within 2 weeks of capture from Texas, Florida and Georgia. All animals were maintained in a $9 \times 9$ m concrete pen which contained 3 community nest boxes and one $1.8 \times 1.8 \mathrm{~m}$ dirt litter area. The diet, which comprised milk, raw meat, wheat bran and raw eggs was provided in excess each evening and replaced with water each morning.

Blood samples from the captive animals were collected by femoral venepuncture under 
ketamine (Ketaset, Bristol Laboratories, $20 \mathrm{mg} / \mathrm{kg}$ ) anaesthesia between 10:00 and 14:00 $\mathrm{h}$. Blood samples from the free-ranging animals were obtained by heart puncture immediately following death by gunshot. All samples were collected with $3 \mathrm{ml}$ syringes containing EDTA ( 3 $\mathrm{mg} / \mathrm{ml}$ ) to prevent clotting, and, after centrifugation, the plasma was stored at $-15^{\circ} \mathrm{C}$ until assayed.

The weights for all captive mature males and free-ranging mature males used in this study ranged from 3.17 to $6.2 \mathrm{~kg}$ and 3.18 to $4.75 \mathrm{~kg}$, respectively. Retrospective evaluation of testicular histology was performed in all animals to assess gonadal function directly.

\section{Hormone assays}

Circulating testosterone levels were measured in $0.1 \mathrm{ml}$ plasma using a modified method of Coyotupa, Parlow \& Abraham (1972). Methodological loss was monitored and accounted for by adding 1000 c.p.m. repurified $\left[{ }^{3} \mathrm{H}\right]$ testosterone before ether extraction and celite column chromatography. Testosterone was eluted in a $5 \mathrm{ml}$ aliquot of cyclohexane:benzene $(95: 5 \mathrm{v} / \mathrm{v})$ from celite:ethylene glycol columns $(2: 1 \mathrm{w} / \mathrm{v})$ after a $10 \mathrm{ml}$ rinse with iso-octane. The testosterone assay was performed by combining 9000 c.p.m. repurified $\left[{ }^{3} \mathrm{H}\right]$ testosterone (sp. act. $98.8 \mathrm{Ci} / \mathrm{mmol}$; New England Nuclear, Boston, Massachusetts) and testosterone antiserum (Abraham, S-791-\#7) in a total incubation volume of $0.7 \mathrm{ml}$ phosphate-buffered saline. The sensitivity of the assay (zero minus $2 \times$ s.d.) was $5 \mathrm{pg} /$ tube or approximately $100 \mathrm{pg} / \mathrm{ml} \mathrm{plasma.}$ The water blank was less than $5 \mathrm{pg} /$ tube and the interassay coefficient of variation for a midrange control serum sample was $10 \%(n=7)$.

Co-chromatography using celite columns was performed by monitoring radioactive and immunoreactive testosterone across the $5 \mathrm{ml}$ cyclohexane-benzene elution at $0.5 \mathrm{ml}$ intervals. Co-chromatography on high-pressure liquid chromatography (hplc) was performed by drying the entire testosterone fraction from the celite column and resuspending in $0.05 \mathrm{ml}$ acetonitrile (Mallinckrodt, St. Louis, Missouri) before injection $(0.02 \mathrm{ml})$ onto a $3.2 \times 250 \mathrm{~mm}$ licrosorb C18 column (Altex) using acetonitrile:water $(40: 60 \mathrm{v} / \mathrm{v})$ as a solvent system. Fractions were collected at $0.3-\mathrm{min}$ intervals for $12 \mathrm{~min}$, blown dry with nitrogen, reconstituted to $1 \mathrm{ml}$ with phosphate buffer then monitored for both recovery and immunoreactivity. Gas-liquid chromatographic verification of testosterone was accomplished by reconstituting the celite column eluate in $0.1 \mathrm{ml}$ carbon disulphide before injection of $0.01 \mathrm{ml}$ onto an OV-17 (80/100) $600 \mathrm{~mm}$ glass column (oven temperature $270^{\circ} \mathrm{C}, \mathrm{N}_{2}$ flow $20 \mathrm{ml} / \mathrm{min}$ ). Flame ionization detection was employed to compare the celite eluate with pure, recrystallized testosterone.

Circulating progesterone, cortisol and corticosterone concentrations were evaluated by individual, specific radioimmunoassays following ether extraction and celite column chromatography. The progesterone antiserum was raised against a progesterone-11-BSA conjugate in this laboratory and the assay was validated for the armadillo as previously described for testosterone. A single antiserum was used for the cortisol and corticosterone assays. This antibody has been previously described for a total glucocorticoid assay (Judd, Parker, Rakoff, Hopper \& Yen, 1973) and demonstrates an $80 \%$ cross-reactivity to corticosterone when compared to cortisol. These assays were performed by following the same protocol as for testosterone and using the appropriate pure and tritiated steroids.

\section{Adrenocorticotrophic hormone infusions}

In order to assess the contribution of adrenal testosterone secretion in response to acute stress, as from blood sampling, infusions of ACTH were performed on 4 long-term captive adult armadillos. Adrenal function was previously suppressed by treatment with dexamethasone (Decadron; Merck, Sharp and Dohme; $1 \mathrm{mg} /$ day) which was administered intramuscularly at 08:00 $\mathrm{h}$ for 4 days up to and including the day of the infusion. The ACTH infusions were 
initiated at 11:00 $\mathrm{h}$ and performed by diluting $20 \mathrm{USP}$ units ACTH (Acthar; Armour Labs) in $30 \mathrm{ml}$ normal saline $(0.9 \%(\mathrm{w} / \mathrm{v}) \mathrm{NaCl})$ and infusing at a rate of $10 \mathrm{ml} / \mathrm{h}$ for $2 \frac{1}{2} \mathrm{~h}$ into the superficial femoral vein by an indwelling catheter while the animals were kept sedated by injections of ketamine. Blood samples were collected at 0, 15, 30, 60, 90 and $150 \mathrm{~min}$ after the start of the infusion by repeated venepuncture of the contralateral femoral vein.

\section{Results}

The celite column elution profile of immunoreactive testosterone in armadillo plasma paralleled that of pure radioactive testosterone indicating that celite separation eliminated most other crossreactive steroids from the plasma in this species since only those steroids with identical retention characteristics would have been present here. Subsequent co-chromatography of the celite eluate using high-pressure liquid chromatography demonstrated similar parallelism and further substantiated this claim. Comparison of gas-liquid chromatographic analysis of the celite eluate with that of a pure testosterone standard provided additional evidence that the major steroid present in the celite fraction is testosterone, since both profiles gave a single peak at $28 \mathrm{~min}$. Calculations of circulating testosterone levels after celite chromatography alone or after celite and high-pressure liquid chromatography in a single sample gave values of 146 and $170 \mathrm{ng} / \mathrm{ml}$ in two separate assays, demonstrating no loss of immunoreactivity due to further purification.

Circulating testosterone levels in captive and free-ranging male armadillos are shown in Table 1. The data for captive animals reflect a 3-year longitudinal study of 6 animals, including 3 males born in captivity 1 year before the start of the study. Testosterone levels in free-ranging males reflect collections throughout a 2-year period. In both groups, the lowest values were found in January and the highest (about $200 \mathrm{ng} / \mathrm{ml}$ ) occurred in May and July. Values in the two groups of animals were mostly similar.

Table 1. Mean \pm s.e.m. circulating testosterone concentrations in captive and free-ranging male armadillos (no. in parentheses) studied over 3 years

\begin{tabular}{lcc}
\hline \multicolumn{1}{c}{ Month } & $\begin{array}{c}\text { Captive } \\
\text { males }\end{array}$ & $\begin{array}{c}\text { Free-ranging } \\
\text { males }\end{array}$ \\
\hline January & $24 \pm 8(5)$ & $20 \pm 10(12)$ \\
February & $84 \pm 20(9)$ & $28 \pm 13(15)$ \\
March & $105 \pm 25(11)$ & $47 \pm 22(5)$ \\
April & $61 \pm 22(8)$ & \\
May & $159 \pm 27(11)$ & $188,242(2)$ \\
June & $138 \pm 28(9)$ & $122 \pm 15(9)$ \\
July & $180 \pm 26(6)$ & $102 \pm 17(10)$ \\
August & $150 \pm 13(12)$ & \\
September & $96 \pm 22(9)$ & $153,165(2)$ \\
October & $107 \pm 18(4)$ & $31,71 \quad(2)$ \\
November & $110 \pm 24(7)$ & \\
December & $69 \pm 17(10)$ & $206,5 \quad(2)$ \\
\hline
\end{tabular}

Text-figure 1 illustrates the changes in testosterone concentrations in immature males born in captivity. At 5 months of age, values were $<10 \mathrm{ng} / \mathrm{ml}$ but rose to $>200 \mathrm{ng} / \mathrm{ml}$ at 16 months and then remained similar to concentrations in adult males.

The hormone changes in response to dexamethasone suppression and subsequent $\mathrm{ACTH}$ stimulation are shown in Text-fig. 2. After dexamethasone treatment, cortisol and corticosterone levels were reduced to approximately $10 \%$ those of untreated control animals which ranged from 15 to $100 \mathrm{ng}$ corticosterone/ml $(n=24)$ and from 60 to $300 \mathrm{ng}$ cortisol $/ \mathrm{ml}(n=24)$. The $\mathrm{ACTH}$ infusion resulted in a 10 - to 20 -fold increase for corticosterone and a 3 - to 100 -fold 


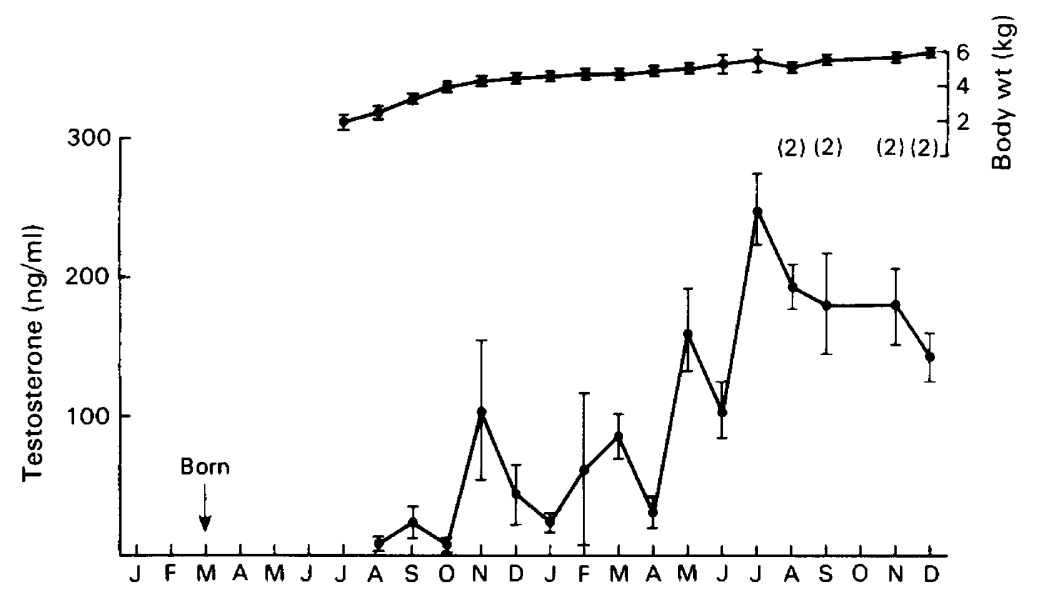

Text-fig. 1. Mean \pm s.e.m. values for circulating testosterone concentrations and body weight of male armadillos born in captivity. There were 3 observations/month except as indicated.

increase for cortisol, thus restoring glucocorticoid levels to the control range in males and females. Progesterone levels were markedly reduced by dexamethasone treatment and restored to pretreatment levels by the ACTH infusion in the female animals. There was little change in progesterone levels throughout the study in the males. Testosterone levels were reduced by 5 -fold

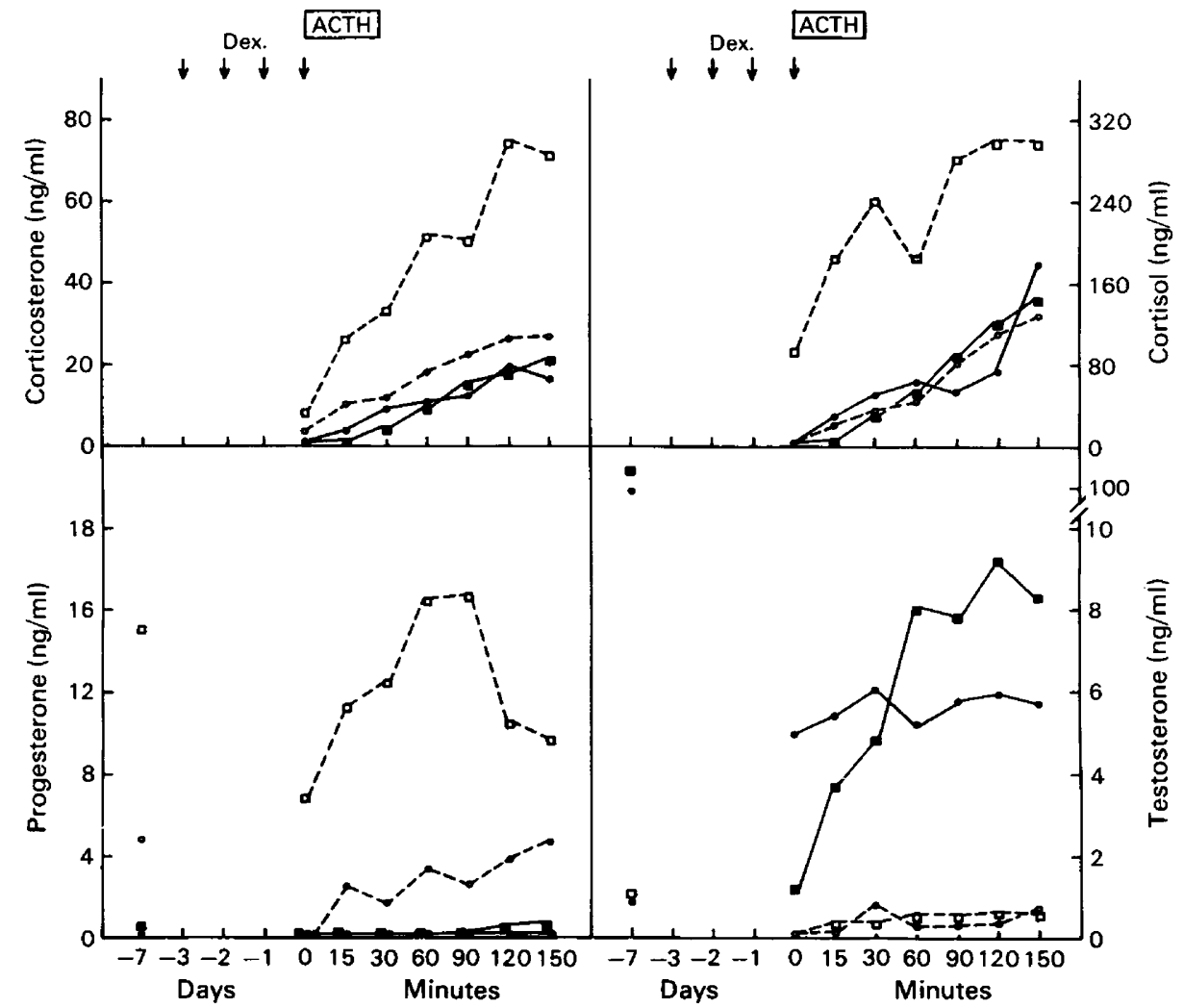

Text-fig. 2. Hormone changes in 2 captive female $(0, \square)$ and 2 captive male $(0, \square)$ armadillos treated with $1.0 \mathrm{mg}$ dexamethasone/day (arrows) and then infused with $6 \mathrm{USP}$ units $\mathrm{ACTH} / \mathrm{h}$. Pretreatment concentrations of progesterone and testosterone are shown. 
(500-700 to $120-150 \mathrm{pg} / \mathrm{ml})$ in the females and $20-100$ fold $(110$ to $1-5 \mathrm{ng} / \mathrm{ml})$ in the male armadillos as a result of dexamethasone treatment. Pretreatment levels of testosterone were reestablished by the ACTH infusion in the females but returned to less than one-tenth of the pretreatment levels in the 2 males.

\section{Testicular histology}

This was identical in captive and free-ranging males at all times of the year.

\section{Discussion}

The application of celite column chromatography to plasma testosterone in the armadillo offers supportive but incomplete verification that this single separation system is adequate to remove all other cross-reacting steroids. The subsequent co-chromatography of the celite fraction by reverse-phase high-pressure liquid chromatography substantiates this assumption since the higher resolution should reveal any cryptic peaks which may have been present in the first system. The final evaluation of chemical purity of the celite fraction by gas-liquid chromatography-flame ionization offers additional support that the celite fraction containing testosterone is relatively free of other organic compounds. Single peaks were found in all three chromatographic systems used and, together, these results provide strong evidence that a valid assay for testosterone has been achieved for the armadillo.

Circulating testosterone levels in free-ranging and captive, mature male armadillos are relatively high when compared with levels in other mammalian species. Men (3-7 ng/ml: Smith, Tcholakian, Chowdhory \& Steinberger, 1974), rhesus monkeys (2-15 ng/ml: Gordon, Rose \& Bernstein, 1976), rams (0.6-9.8 ng/ml: Schanbacher \& Ford, 1976), black bears $(0.5-1.5$ $\mathrm{ng} / \mathrm{ml}$ : McMillan et al., 1976) and lemurs (2-30 ng/ml: Bogart et al., 1977) exhibit maximum testosterone concentrations near or below the lowest levels found throughout the year in the male armadillo. Testosterone levels of $100-200 \mathrm{ng} / \mathrm{ml}$ during the breeding season in the male armadillo therefore represent some of the highest values yet reported and are approached only by the testosterone levels reported in the marmoset $(50 \mathrm{ng} / \mathrm{ml}$ : Abbott \& Hearn, 1978) and androgen levels in the squirrel monkey $(58 \mathrm{ng} / \mathrm{ml}$ : Wilson, Brown \& Wilson, 1978).

Although an adrenal contribution to these high circulating testosterone levels has not been directly excluded, the results shown in Text-fig. 2 do suggest that the production of significant amounts of testosterone by the adrenal gland in the male armadillo is unlikely. The marked reduction in both cortisol and corticosterone levels achieved by the dexamethasone treatment indicates that adrenal function was effectively inhibited in all animals. Testosterone production was also inhibited in both males and females. Although this latter effect may be interpreted to mean that much of the testosterone was of adrenal origin, the results of the ACTH infusion in males do in fact suggest a testicular origin. Whereas testosterone concentrations in females were restored to pre-suppression levels by the ACTH infusion, the testosterone increment in males was minimal, with levels remaining less than $10 \%$ of pre-dexamethasone values. Since the glucocorticoid responses to ACTH indicate that normal adrenal function had been restored, the disparity of testosterone levels between male and female animals indicates that the majority $(>90 \%)$ of the circulating testosterone in the males is of testicular origin. The reduction in testosterone levels caused by the initial dexamethasone treatment could therefore be explained by a direct action on the testis as previously suggested in men (Schaison, Durand \& Mowszowicz, 1978). The increase in testosterone concentrations coinciding with the onset of the breeding season, together with the continuous abundance of smooth endoplasmic reticulum in the Leydig cells and persistence of active spermatogenesis throughout the year (Weaker, 1977) further support the hypothesis that substantial amounts of testosterone are continuously produced by the testes of this species. 
The present data indicate a marked sex difference in adrenal progesterone production in captive armadillos since, in the female, a substantial proportion of the high circulating progesterone concentrations is derived from the adrenal gland and is responsive to ACTH (Textfig. 2).

Circulating testosterone levels in captive male armadillos were similar to or higher than those found in free-ranging males at all times in the year (Table 1). This is a relatively important issue when the problems of captive breeding of this species are considered and these data would suggest that this problem is not due to hypogonadal function of the male. Apart from the similar testicular histology sperm-rich ejaculates with high sperm motility have been collected by electro-ejaculation from males maintained in captivity for up to 3 years and such males have copulated with and inseminated captive females treated with ovulatory doses of PMSG (unpublished observations).

Testosterone levels in captive-born male armadillos during the first 7 months of life were lower than those of adult males (Text-fig. 1), but were then higher because values in adults declined after the breeding season. By 1 year of age, testosterone concentrations in young males are indistinguishable from those of older animals. As with males captured as adults, males born and reared in captivity show no apparent gonadal defect.

We thank Mr Ronald Schwartz for animal care and Ms Kay Nakakura for technical assistance. The work was supported by NIH grant HD 10190.

\section{References}

Abbott, D.H. \& Hearn, J.P. (1978) Physical, hormonal and behavioural aspects of sexual development in the marmoset monkey, Callithrix jacchus. J. Reprod. Fert. 53, 155-166.

Bogart, M.H., Kumamoto, A.T. \& Lasley, B.L. (1977) A comparison of the reproductive cycle of three species of lemur. Folia Primatol.28, 134-143.

Coyotupa, J., Parlow, A.F. \& Abraham, G.E. (1972) Simultaneous radioimmunoassay of plasma testosterone and dihydrotestosterone. Analyt. Lett. 5, 329.

Gordon, T.P., Rose, R.M. \& Bernstein, I.S. (1976) Seasonal rhythm in plasma testosterone levels in the rhesus monkey (Macaca mulatta): a three year study. Horm. Behav. 7, 229-243.

Hamlett, G.W.D. (1932) The reproductive cycle of the armadillo. Z. wiss. Zool. (Abt. A), 143-157.

Judd, H.L. Parker, D.C., Rakoff, J.S., Hopper, B.R. \& Yen, S.S.C. (1973) Elucidation of mechanisms of the nocturnal rise of testosterone in men. J. clin. Endocr. Metab. 38, 134-141.

McCusker, J.S. (1976) The nine-banded armadillo (Dasypus novemcinctus) in north central Texas with emphasis on the reproductive biology of the male. Master's dissertation, Texas Christian University.

McMillan, J.M., Seal, U.S., Rogers, L. Erickson, A.W.
(1976) Annual testosterone rhythm in the black bear (Ursus americanus). Biol. Reprod. 15, 163-167.

Neal, J., Murphy, B.D., Moger, W.H. \& Oliphant, L.W. (1977) Reproduction in the male ferret: gonadal activity during the annual cycle; recrudescence and maturation. Biol. Reprod. 17, 380-385.

Schaison, G., Durand, F. \& Mowszowicz (1978) Effect of glucocorticoids on plasma testosterone in man. Acta endocr., Copenh. 89, 126-131.

Schanbacher, B.D. \& Ford, J.J. (1976) Seasonal profiles of plasma luteinizing hormone, testosterone and estradiol in the ram. Endocrinology 99, 752-757.

Smith, K.D., Tcholakian, R.K., Chowdhory, M. \& Steinberger, E. (1974) Rapid oscillations in plasma levels of testosterone, luteinizing hormone, and follicle-stimulating hormone in men. Fert. Steril. 25, 965-975.

Weaker, FJ. (1977). The fine structure of the interstitial tissue of the testes of the nine-banded armadillo. Anat. Rec. 187, 11-28

Wilson, M.I., Brown, G.M. \& Wilson, D. (1978) Annual and diurnal changes in plasma androgen and cortisol in adult male squirrel monkeys (Saimiri sciureus) studied longitudinally. Acta endocr., Copenh. 87, 424-433. 